\title{
Health Monitoring of Russian University Staff
}

\author{
AV Zharova ${ }^{1}$, MA Lisnyak ${ }^{2}$, NA Gorbach ${ }^{* 2}$ and GN Goncharova ${ }^{1}$ \\ ${ }^{1}$ Russian Federation, Krasnoyarsk \\ ${ }^{2}$ Federal state budgetary educational institution of higher education, Krasnoyarsk \\ 3Reshetnev Siberian State University of Science and Technology, Krasnoyarsk
}

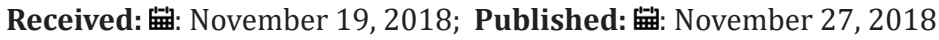

*Corresponding author: NA Gorbach, Federal state budgetary educational institution of higher education, Krasnoyarsk

\section{Opinion}

University staff remain one of the most vulnerable occupational groups, despite the measures taken by the government as a form of social support. Having a high level of education and qualifications, many university professors are forced to search for the sources of additional income. It leads to intellectual and physical overload, reduces the possibilities of full recovery from work. Certainly, this adversely affects people's health. A study of 150 Medical University professors conducted in June 2018 as a part of periodic medical examinations revealed the following: only $14.0 \pm 2.8 \%$ of the respondents have no disease and their health is excellent;

a) $\quad 64.7 \pm 3.9 \%$ of the respondents hardly ever suffer from diseases;

b) $18.0 \pm 3.1 \%$ of the respondents suffer from frequent diseases and often feel ill;

c) $3.3 \pm 1.4 \%$ of respondents have chronic diseases and constantly feel unwell.

It should be noted that these are self-reported data, but the unbiased picture of the university staff health can be much worse. The results of the earlier studies of the same type correspond with the data obtained (N. A. Gorbach, 2010; M. A. Lisnyak, 2017).

In order to preserve the labor potential of highly qualified university staff, the state in general and the administration of higher educational institutions should organize university staff health monitoring. It will make it possible to track the dynamics of both individual and occupational group health, which is important for identifying and controlling the influence of factors (for example, workload increasing) on university staff health. When monitoring the researchers should consider not only the somatic health (by objective and subjective indicators), but also their mental wellbeing, namely the emotional burnout level. Periodic medical examinations performed once a year are regulated by Order $302 \mathrm{n}$ released by Russian Federation Health and Social Development Ministry on April 12, 2011 "On approving the lists of hazardous and (or) dangerous occupational factors and works that require obligatory preliminary and periodic medical examinations (workup) and on regimen of obligatory preliminary and periodic medical examinations (workup) for workers exposed to intense labor and to hazardous and (or) dangerous work conditions". University stuff fall into the category "Work in educational organizations of all types and kinds, as well as non-educational organizations for children (sports clubs, leisure centers, etc.)" (Paragraph 18, Appendix 2). In our opinion, it is not entirely correct the assign university stuff to this group. Some of the medical tests in the above order are redundant, for example, helminthiasis or bacterial infections tests. Unlike school teachers, university professors communicate with adult citizens who have personal hygiene skills.

On the other hand, the medical examination standard doesn't include an examination by a neurologist or an oculist. The peculiarities of university occupational activity are that it is relatively inactive, but full of information and emotions, moreover it includes eye strain (M. A. Lisnyak, 2011). Therefore, it is reasonable to monitor the general health condition using an integral indicator (health group, health index, etc.), as well as the results of examinations by a cardiologist, a neurologist, and an ophthalmologist. It is important to study the following aspects for mental health monitoring:
a) Personal characteristics;
b) Coping strategies;
c) Adaptation ability, psychological and emotional strain level. 
In addition, it is important to monitor the emotional burnout level of university staff (Boyko method) and the manifestations of occupational stress.

To obtain a coherent and unbiased picture, monitoring should be carried out by an independent structure that is not connected with any higher educational institution in a city. A prime example of this can be the Center for University Hygiene and Health which is worthwhile to establish based on a multipurpose hospital unit with a polyclinic department. The choice of the base is due to

ISSN: 2574-1241

DOI: 10.26717/BJSTR.2018.11.002105

NA Gorbach. Biomed J Sci \& Tech Res

This work is licensed under Creative Commons Attribution 4.0 License

Submission Link: https://biomedres.us/submit-manuscript.php qualified specialists' availability who are able both to process the monitoring results and develop individual and group rehabilitation programs for university staff using the resources of a treatment and prevention establishment. University medical centers will continue to carry out their work; they will however coordinate their plans with the Center and receive their methodological support. Certainly, for enabling the Center's full coordination of the university medical centers, it will be necessary to create a new regulatory framework managing this interaction, which is possible only at the state level.

$\begin{array}{ll}\text { BIOMEDICAL } & \text { Assets of Publishing with us } \\ \text { RESEARCHES } & \text { - Global archiving of articles } \\ & \text { - Immediate, unrestricted online access } \\ & \text { - Rigorous Peer Review Process } \\ \end{array}$

